\title{
THE USE OF VIRTUAL REALITY MODELS IN CIVIL ENGINEERING TRAINING
}

\author{
Sampaio, A. Z. \& Henriques, P. G. \\ Department of Civil Engineering and Architecture, ICIST, Technical University of Lisbon, \\ Av. Rovisco Pais, 1049-001 Lisbon, Portugal \\ E-Mail: zita@civil.ist.utl.pt; pgameiro@civil.ist.utl.pt
}

\begin{abstract}
Virtual Reality techniques were used to develop educational didactic models in the area of Civil Engineering. The visualization of the distinct physical steps of a construction is shown in the virtual applications here presented. The developed models bring new perspectives in the teaching activity as a support to expose new curricular programmes or complex sequence construction. In order to obtain models, which would be able to visually simulate the geometric evolution of the construction activity, techniques of geometric modelling and virtual reality were used. The models make it possible to view the physical evolution of the work, to follow the planned construction sequence and to visualize details of the form of every component of the works. They also support the study of the type and method of operation of the equipment necessary for these construction procedures. These models have been used to distinct advantage as educational aids in first-degree courses in Civil Engineering. (Extended paper from the International Symposium CompIMAGE - Coimbra, Portugal, 20-21 October 2006.)
\end{abstract}

Key Words: Engineering Education, Visual Simulation, Virtual Reality, 4D Models

\section{INTRODUCTION}

Normally, three-dimensional (3D) geometric models, which are used to present architectural and engineering works, show only their final form, not allowing the observation of their physical evolution. The 3D representation of the building, with an animated walk-through, just allows the observation of both its interior and exterior. Also, existing educational courseware are not designed to follow changes in geometry of the building or structure during the construction process. But, the visual simulation of the construction process needs to be able to produce changes to the geometry of the project dynamically.

Traditional construction planning tools, such as bar charts and network diagrams, do not represent and communicate the spatial and temporal, or four-dimensional, aspects of construction schedules effectively. The integration of geometrical representations of the building together with scheduling data is the bases of 4D (3D + time) models in construction domain. Extending the traditional planning tools, visual 4D models combine 3D CAD models with construction activities to display the progression of construction over time [1]. The Centre for Integrated Facility for Engineering, leaded by M. Fischer, has tested the usefulness of visual 4D models in planning the construction of buildings (hospital, university, commercial building). These cases have shown that more project stakeholders can understand a construction schedule more quickly and completely with 4D visualization than with the traditional construction management tools [2]. VTT Building Technology has been developing and implementing applications based on Virtual Reality (VR [3]) technology and 4D to improve construction management practice [4]. 
It is then important to extend the usefulness of design information to the construction planning and construction phases [5]. In the present study, two engineering construction work virtual 4D models were created, from which it was possible to obtain 3D models corresponding to different states of their configuration, simulating distinct stages in their construction. They show the physical state of the construction work, step-by-step with the time planned for each type of work. The targets of these models are Civil Engineering students. The use of techniques of VR in the development of these educational applications brings new perspectives to the teaching of subjects in this area.

The developed applications refer to the construction of a masonry cavity wall and a bridge. These models make it possible to show the physical evolution of the work, the monitoring of the planned construction sequence, and the visualization of details of the form of every component of each construction. They also assist the study of the type and method of operation of the equipment necessary for these construction procedures.

\section{DIDACTIC MODELS}

One of the applications developed corresponds to the model of a masonry cavity wall, one of the basic components of a standard construction. To enable the visual simulation of the construction of the wall, the geometric model generated is composed of a set of elements, each representing one component of the construction. Using a system of VR technologies, specific properties appropriate to the virtual environment are applied to the model of the wall. Through direct interaction with the model, it is possible both to monitor the progress of the construction process of the wall and to access information relating to each element, namely, its composition and the phase of execution or assembly of the actual work, and compare it with the planned schedule. This model had been used to distinct advantage as an educational aid in Civil Engineering degree course modules.

The second model created allows the visual simulation of the construction of a bridge using the cantilever method. The geometric model of the bridge deck was created through a bridge deck modelling system, implemented as part of a research project at Department of Civil Engineering and Architecture, Technical University of Lisbon. A system of VR was used to program the visual simulation of the bridge construction activities. Students are able to interact with the model dictating the rhythm of the process, which allows them to observe details of the advanced equipment and of the elements of the bridge (pillars, deck and abutments). The sequence is defined according to the norms of planning in this type of work. The aim of the practical application of the virtual model of bridge construction is to provide support in those disciplines relating to bridges and construction process.

The virtual models are oriented to teaching construction techniques by means of virtual environments and it is expected that they will be able to contribute to support teaching disciplines concerned with Civil Engineering. For this purpose they can be manipulated interactively allowing the user to monitor the physical evolution of the work and the construction activities inherent in its progression. In this way, the models allow students to learn about construction planning of the specific situations presented. Another objective in creating this kind of virtual applications is to show in which way new technologies afford fresh perspectives for the development of new tools in the training of construction processes. The virtual models can be very useful both in face-to-face classes and in distance learning using e-learning technology. 


\section{VIRTUAL MODEL OF THE WALL'S CONSTRUCTION}

Described here are the processes both of the modelling of an exterior wall of a standard building and of the association of virtual properties with the created model, the intended outcome being the interactive exhibition of its construction [6]. The model of the masonry cavity wall, including the structure of the surrounding reinforced concrete and the elements in the hollow area (bay elements), was created using a three dimensional graphic modelling system in widespread use in planning offices, namely, AutoCAD. The virtual environment was applied to the model through the computer program EON Reality system [7].

\subsection{Modelling the construction components of the wall}

The representation of the model of an exterior wall of a conventional building comprises the structural elements (foundations, columns and beams), the vertical filler panels and two bay elements (door and window). In order to provide the virtual simulation of the geometric evolution of a wall in construction, the 3D model was defined as a set of individual objects, each one representing a wall component. So, the virtual model allows the student to learn about the construction evolution concerning to an important part of a conventional building.

The structural elements (demarking the brick panels) of the model were created with parallelepipeds and were connected according to their usual placement in building works. Because this is an educational model, the steel reinforcements were also defined. In the model, the rods of each reinforcement are shown as tubular components with circular cross-section. Fig. 1 shows the way to accommodate the steel reinforcements inside the structural elements. This is a real problem that is solved for each case in the work place. The steel elements were modelled taking into account the complexity of there allocation. It is then an illustrative and a didactic example.
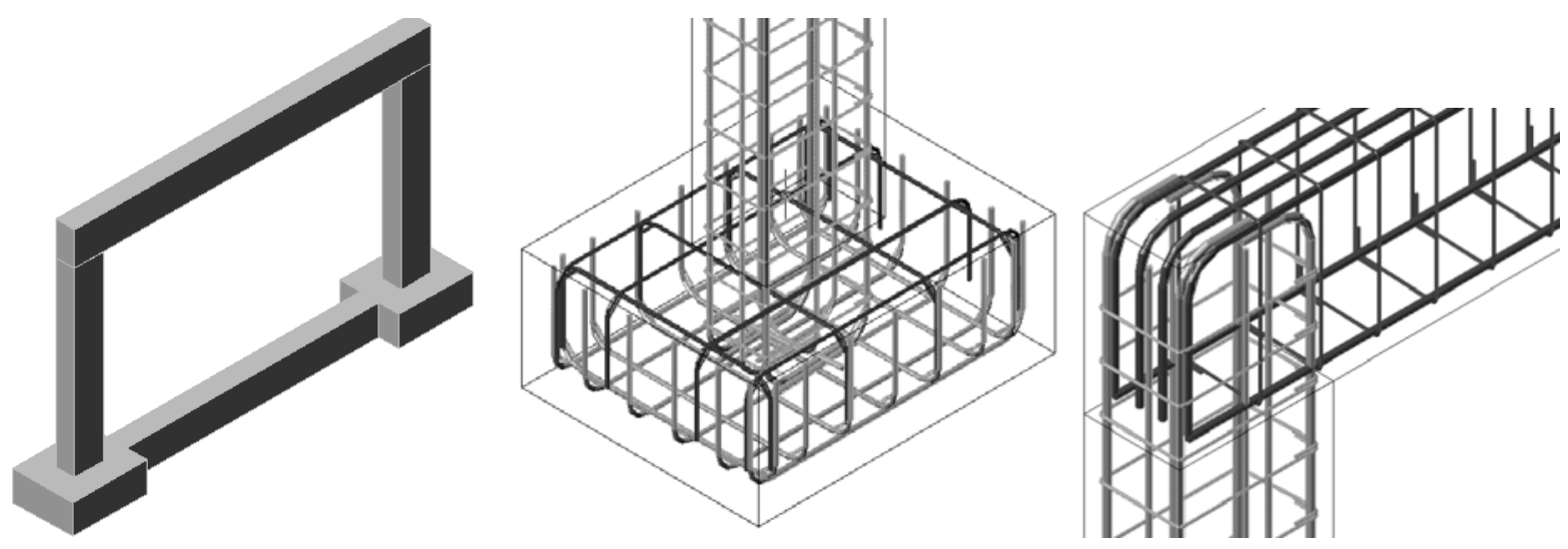

Figure 1: Details of the structural elements of the 3D model.

The type of masonry selected corresponds to an external wall formed by a double panel of breezeblocks, $11 \mathrm{~cm}$, wide with an air cavity, $6 \mathrm{~cm}$, wide (Fig. 2). Complementary to this, the vertical panels were modelled, these comprising: the thermal isolation plate placed between the brick panels; the plaster applied to the external surface of the wall; the stucco applied on the internal surface; two coats of paint both inside and out and the stone slabs placed on the exterior surface. Finally, two usual bay elements, a door and a window, were modelled (Fig. 2). The completed model was then transferred to the virtual reality system EON (as a design file with $3 d s$ extension, Fig. 2). 

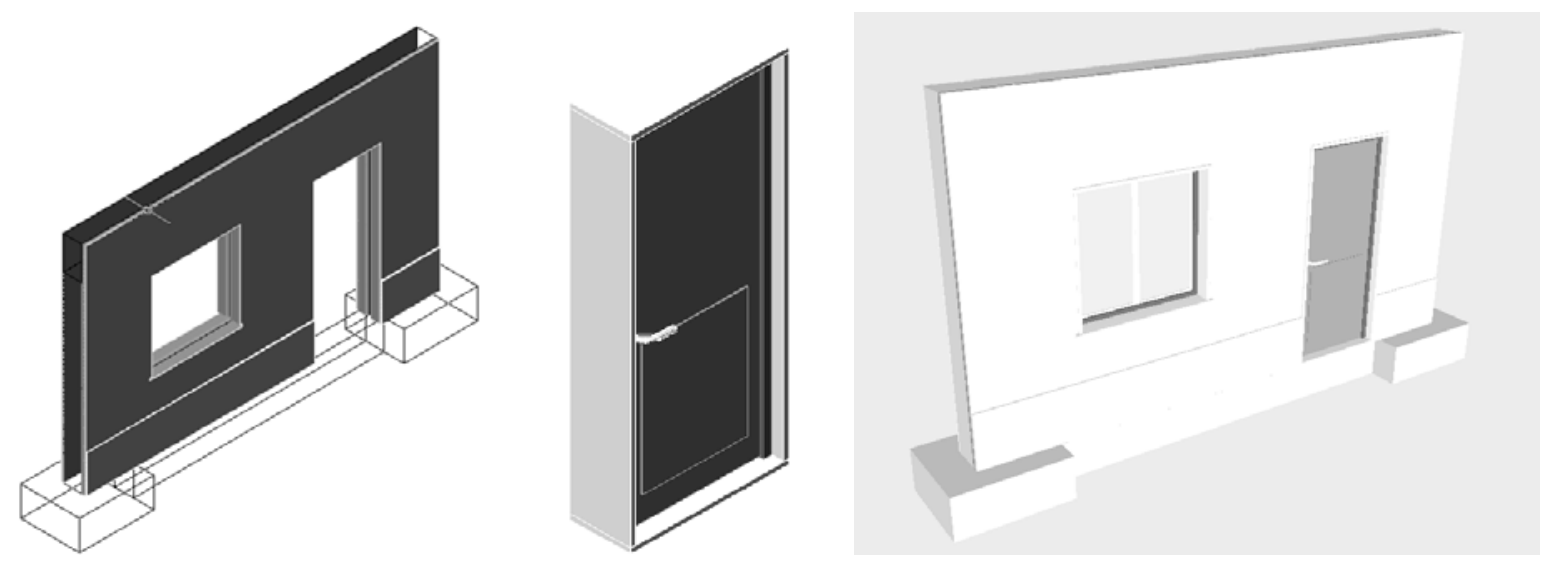

Figure 2: Details of the vertical panels and the door and the complete 3D model of the wall.

\subsection{Programming the Virtual Scenario}

Fig. 3 presents the main window of the EON system:

- The sub-window to the left contains a table of nodes or actions (of movement, sensors, etc.) available in this system;

- The centre sub-window is designated a simulation tree. The objects making up a given scenario are presented in it, and the links between each object or group and the actions to be taken associated to each of them are also shown. It is therefore, through the use of this window that the simulation of the desired virtual action is programmed;

- In the sub-window on the right, the links between the various nodes are established thus defining a network. In this network the nodes where the links originate and terminate are identified, as is the means of setting each action in motion.

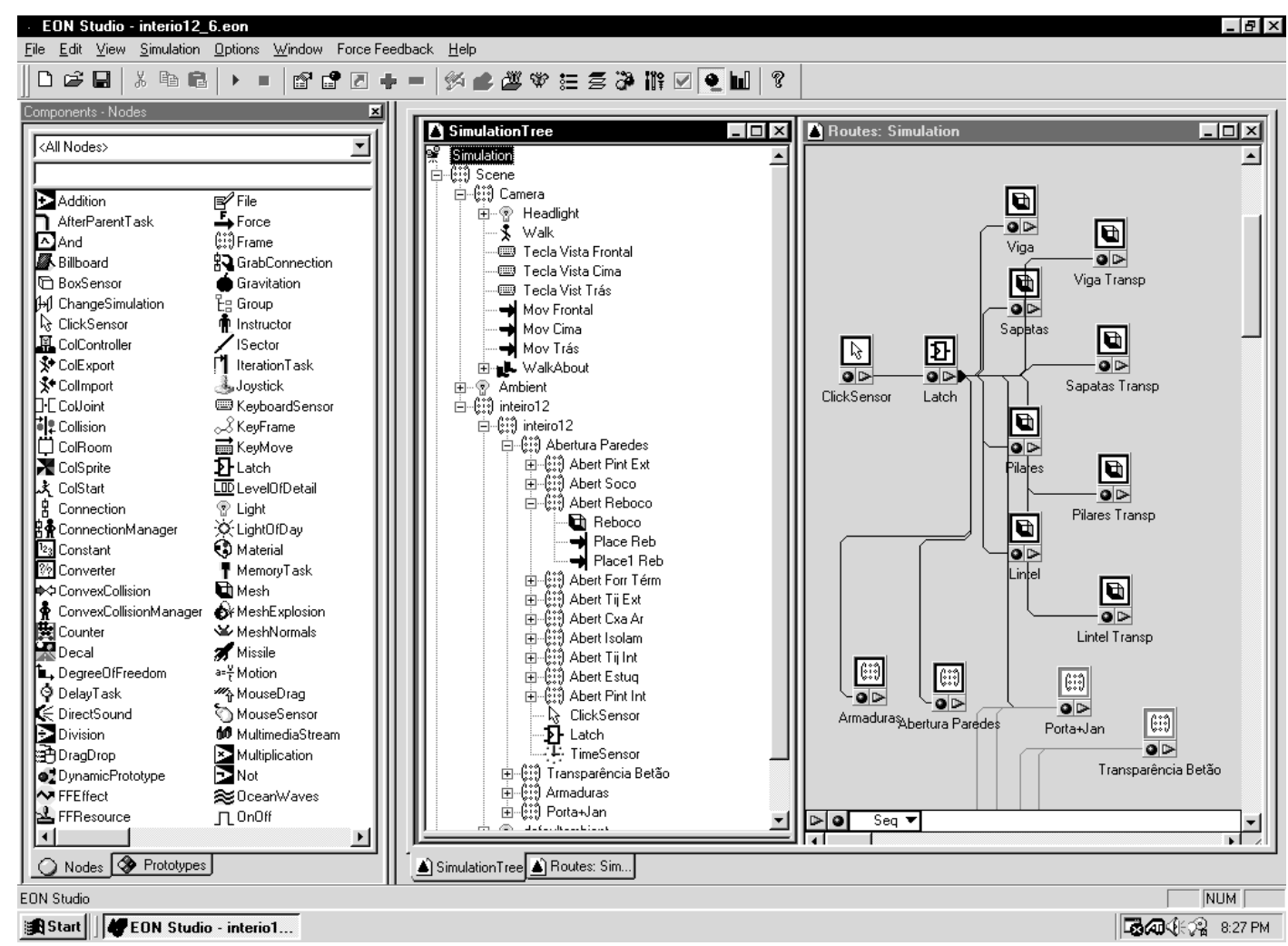

Figure 3: The main window of the EON Studio system. 
When the 3D model is inserted into the VR system, the drawing blocks of the model are identified in the central window. To define an animated presentation the nodes or actions needed are picked from the nodes window and put into the simulation tree. Here, those nodes are associated to the blocks to be affected by the programmed animation.

The exhibition of the several vertical panels of the wall presented in explosion is a kind of animation with a great didactic interest. Fig. 4 includes two steps of this presentation, the opened and closed situations. The translation displacement value attributed to each panel was distinct from each other in order to obtain an adequate explosion presentation. This type of animation allows the student to understand the correct sequence of the vertical panels in a wall and to observe the different thickness of each one.
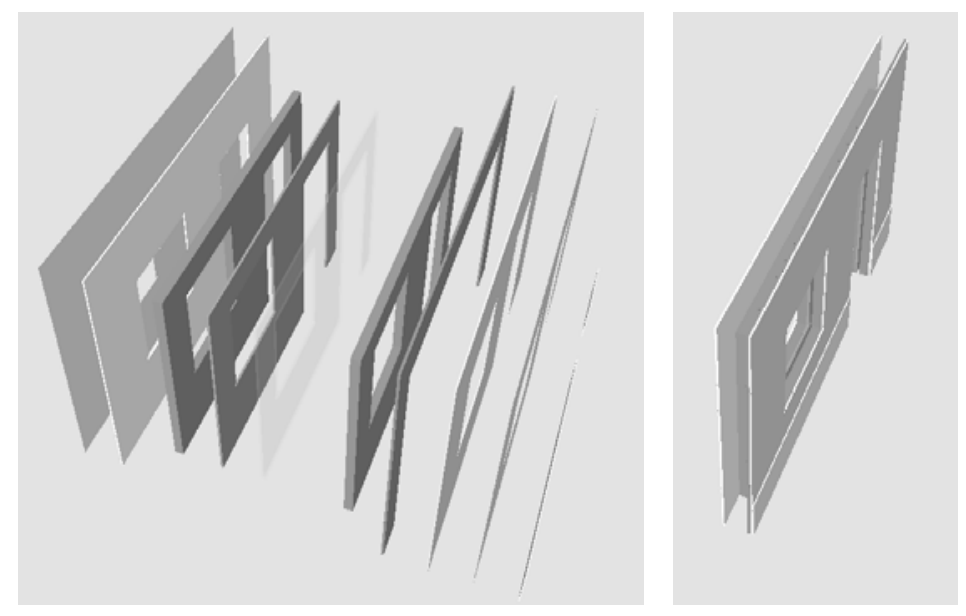

Figure 4: Vertical panels presented in explosion.

In the EON system, the visual simulation of the building process of the wall, following a particular plan, was programmed. For this effect, 23 phases of construction were considered. The order in which components are consecutively exhibited and incorporated into the virtual model, translates into the method of the physical evolution of the wall under construction (Fig. 5).
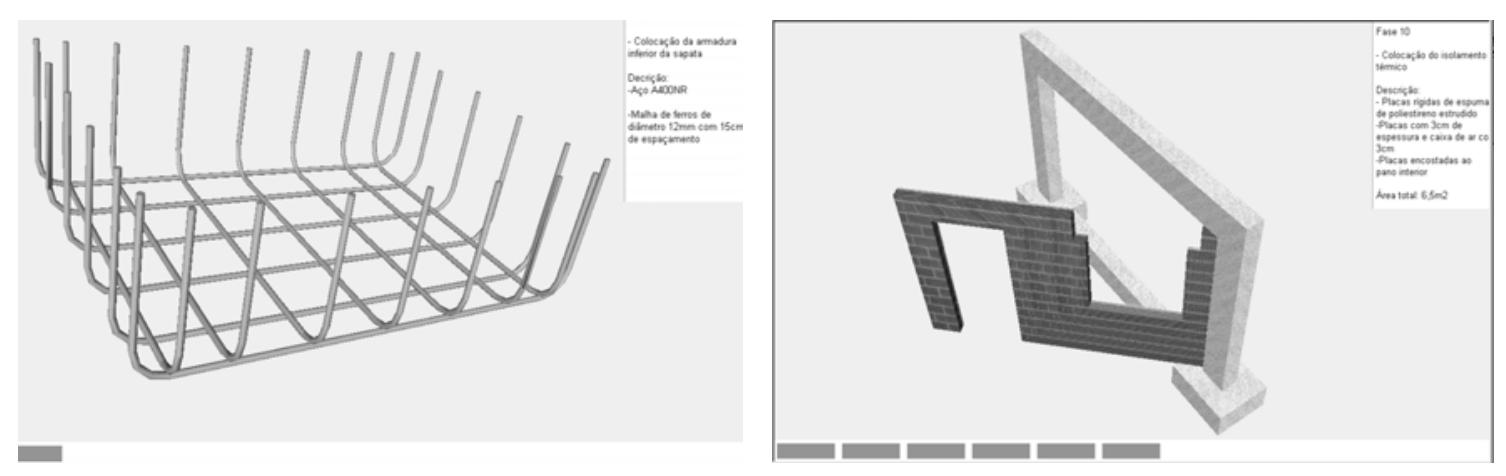

Figure 5: Exhibition of phases in building evolution.

During the animation, the student can control the length of time that any phase is exhibited and observe the model using the most suitable camera and zoom positions for a correct perception of the details of construction elements. It is possible to highlight the component incorporated at each new phase and to examine it in detail (Fig. 6). Included, under the window in which the virtual scene is exhibited, is a bar, which shows the progress of the construction. Throughout the animation, the bar is filled, progressively, with small rectangles symbolizing 
the percentage built at the time of the viewing of that particular phase, in relation to the completed wall construction (Fig. 6). The students can pick a previous step in the bar and the virtual scenario turn back to the corresponding construction phase.
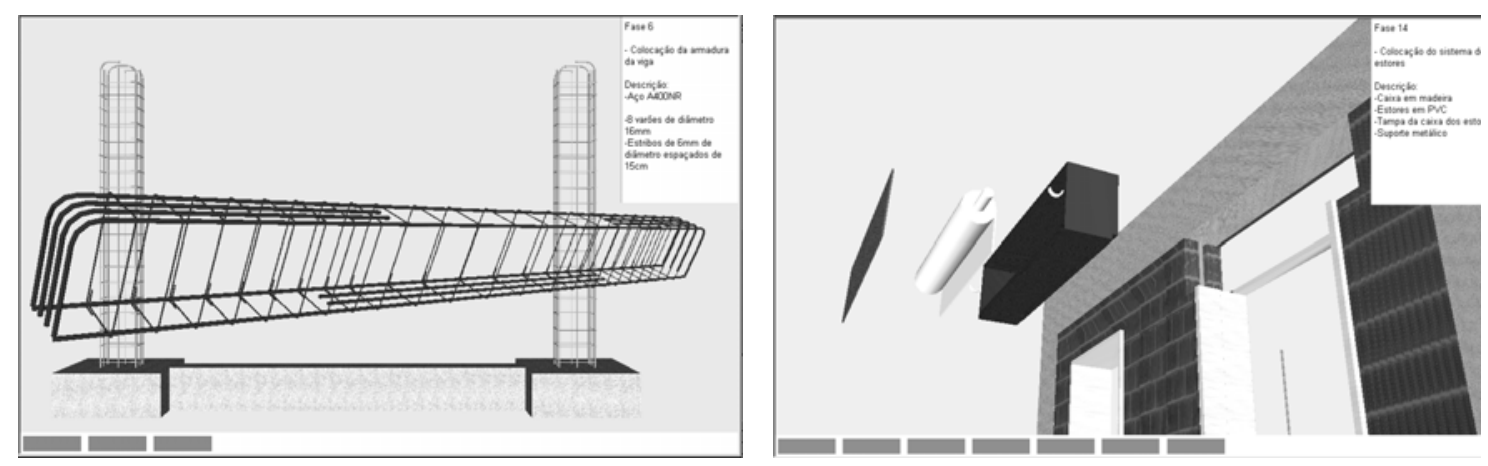

Figure 6: Elements displaced from the global model of the wall.

Simultaneously, with the visualization of each phase, a text is shown (in the upper right corner of the window, Fig. 7) giving data relating to the stage being shown, namely, its position within the construction sequence, the description of the activity and the characterization of the material of the component being incorporated. These are important information to civil engineering students.

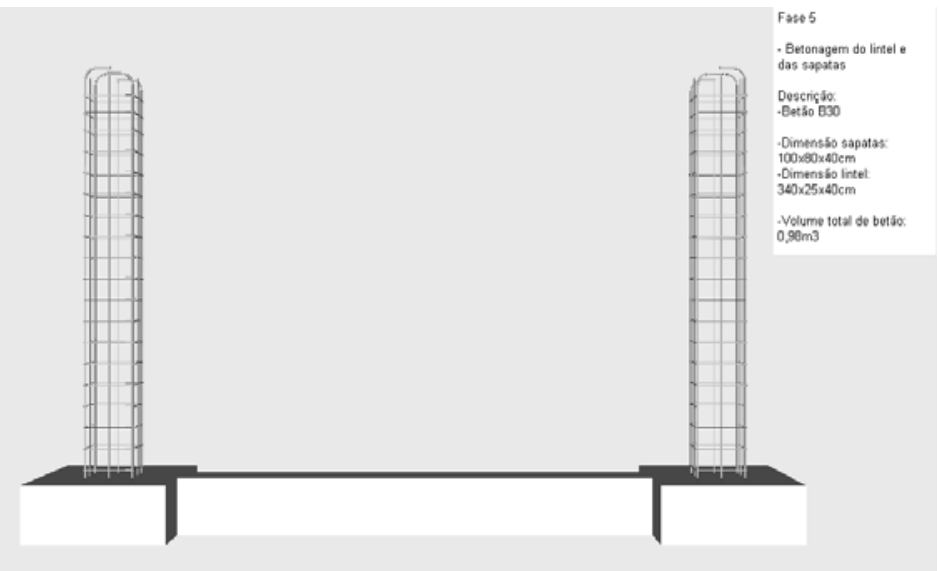

Phase 5
Cementing the lintel
and foundation
Description:
Cement B30
Dimension of the
foundations:
100x80x40cm3
Dimensions of the
lintel cross section:
$25 x 40 \mathrm{~cm} 2$
Total volume of
cement:
$0.98 \mathrm{~cm} 3$

Figure 7: Presentation of text describing the exhibited phase.

\section{VIRTUAL MODEL OF THE BRIDGE DECK'S CONSTRUCTION}

Throughout the bridge research project, a system of computer graphics was used [8]. This system enables the geometric modelling of a bridge deck of box girder typology. It was used to generate, 3D models of deck segments necessary for the visual simulation of the construction of the bridge [9]. The attribution of virtual properties to the model of the bridge was implemented by using the virtual reality system EON Studio.

From amongst the examples of bridge decks modelled through the use of the graphic system for bridges, the North Viaduct of the Quinta Bridge in Madeira, Portugal, was the case selected for representation in the virtual environment. In cross-section, the deck of the viaduct shows a box girder solution and its height varies in a parabolic way along its three spans. The most common construction technique for this typology is the cantilever method of deck construction. This method starts by applying concrete to a first segment placed over each pillar, 
the segment being long enough to install on it the work equipment. The construction of the deck proceeds with the symmetrical positioning of the segments starting from each pillar. The continuation of the deck, uniting the cantilever spans, is completed with the positioning of the closing segment.

In order to be able to manipulate the construction work of the bridge in virtual reality, in addition to the 3D models of each segment, models of the pillars, form travellers, abutments and false work were made. The spans were created through the use of the representational system for bridges mentioned above and the remaining components through AutoCAD system. All the components of the construction scenario were transposed to the VR system, proceeding, then, to the definition of the desired animation.

\subsection{Modelling the elements of the construction scenario}

Geometric description data can be entered directly into the deck-modelling program. To achieve this, the developed interface presents diagrams linked to parameters of the dimensions, so facilitating the description of the geometry established for each concrete case of the deck. The image included in Fig. 8 shows the interface corresponding to the cross-section of the deck of the example.

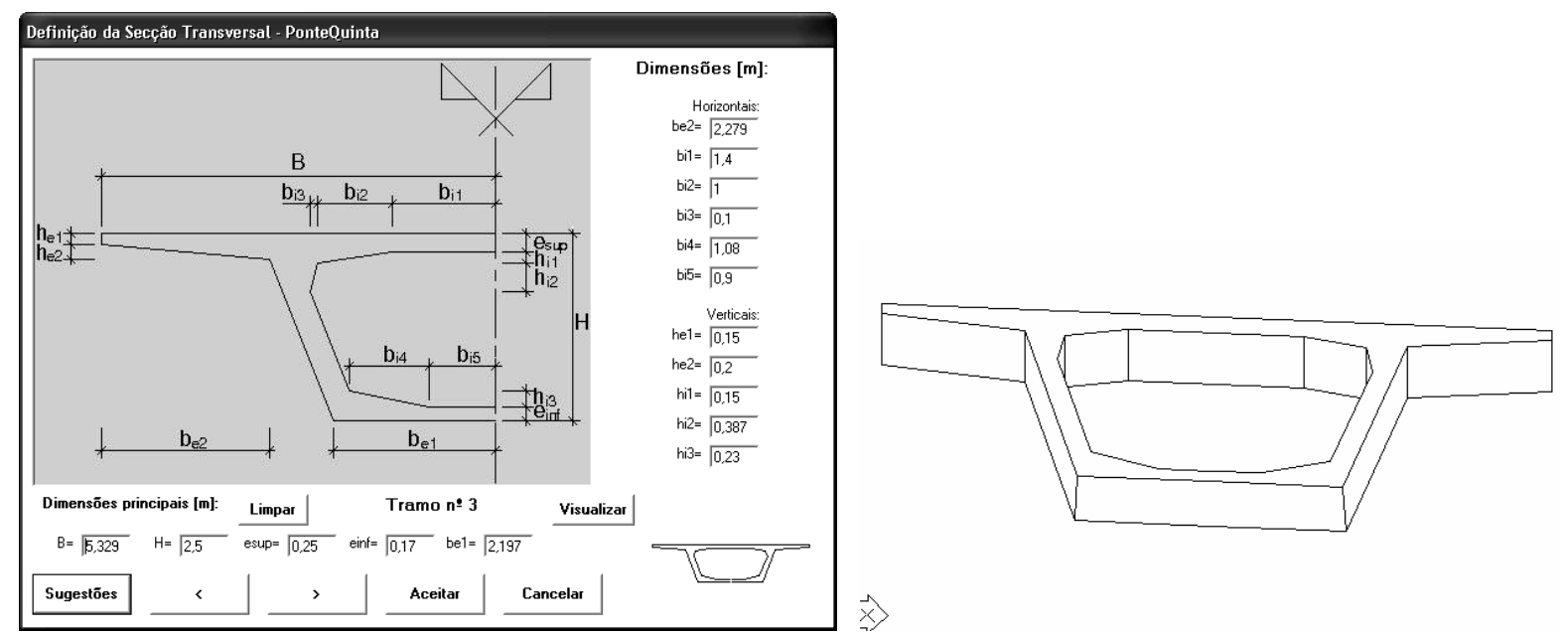

Figure 8: Interface of the description of the cross-section of the deck and the projection of the 3D model of a deck segment.

The description of the longitudinal morphology of the deck and the geometry of the delineation of the service road, serving the zone where the bridge is to be built is carried out in the same way. The configuration and the spatial positioning of each are obtained with a high degree of accuracy. To obtain the definition of the deck segment models, consecutive sections corresponding to the construction joints are used. The configuration presented by the segment models is rigorously exact. Fig. 8 shows one of the segments of the deck. To complete the model of the bridge, the pillars and abutments were modelled. Based on research in the literature concerning abutments for the typology of box-girder decks, a model was created as shown in Fig. 9. Then followed the modelling of the advanced equipment, which is composed not only of the form traveller, but also the formwork adaptable to the size of each segment, the work platforms for each formwork and the rails along which the carriages run (Fig. 9).

As, along with the abutments, the deck is concreted with the false work on the ground, the scaffolding for placement at each end of the deck was also modelled (Fig. 10). Terrain suitable for the simulation of the positioning of the bridge on its foundations was also modelled. 
Bridge designers and bridge construction equipment web sites were consulted in order to define the 3D models and how to manage the construction equipment [10].
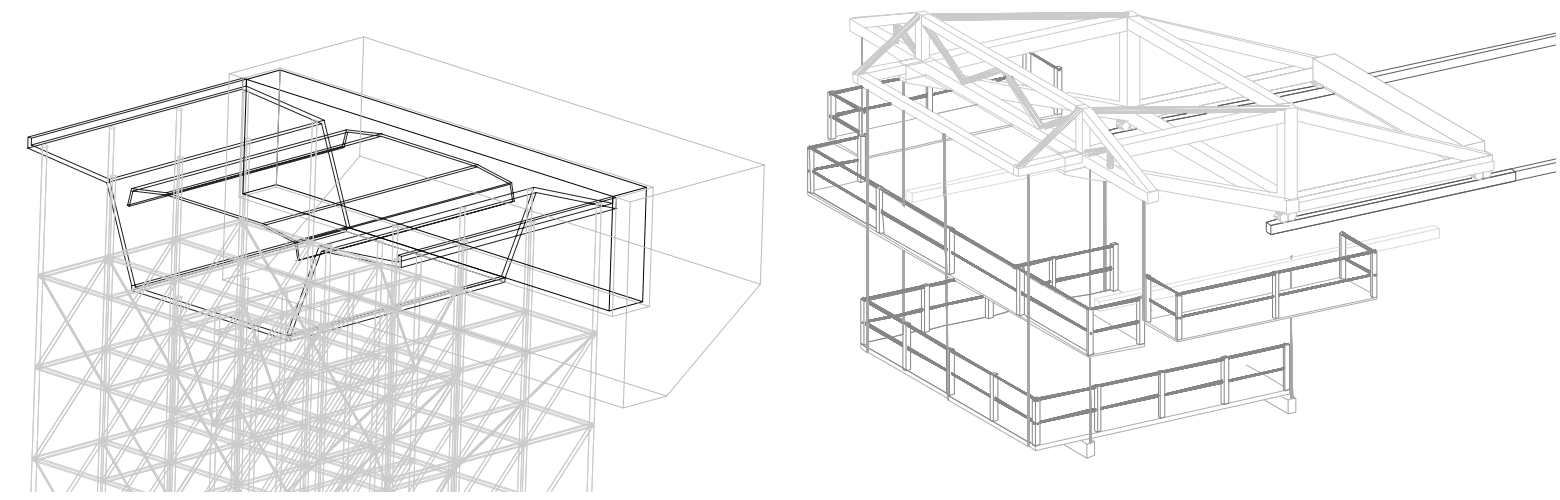

Figure 9: Projections of the 3D models of the abutments, false work, scaffolding and equipment.

\subsection{Programming the Virtual Construction}

Once all the 3D models of the construction scenario had been generated, they were transposed, in 3ds extension data file format, to the VR system. The definition of the construction sequence is based on a counter, which determines the next action when a mouse button is clicked. The first action consists of the insertion of the pillars in the first scenario, which is composed solely of the landscape. The next step is to place one of the segments on top of each of the pillars (Fig. 10).
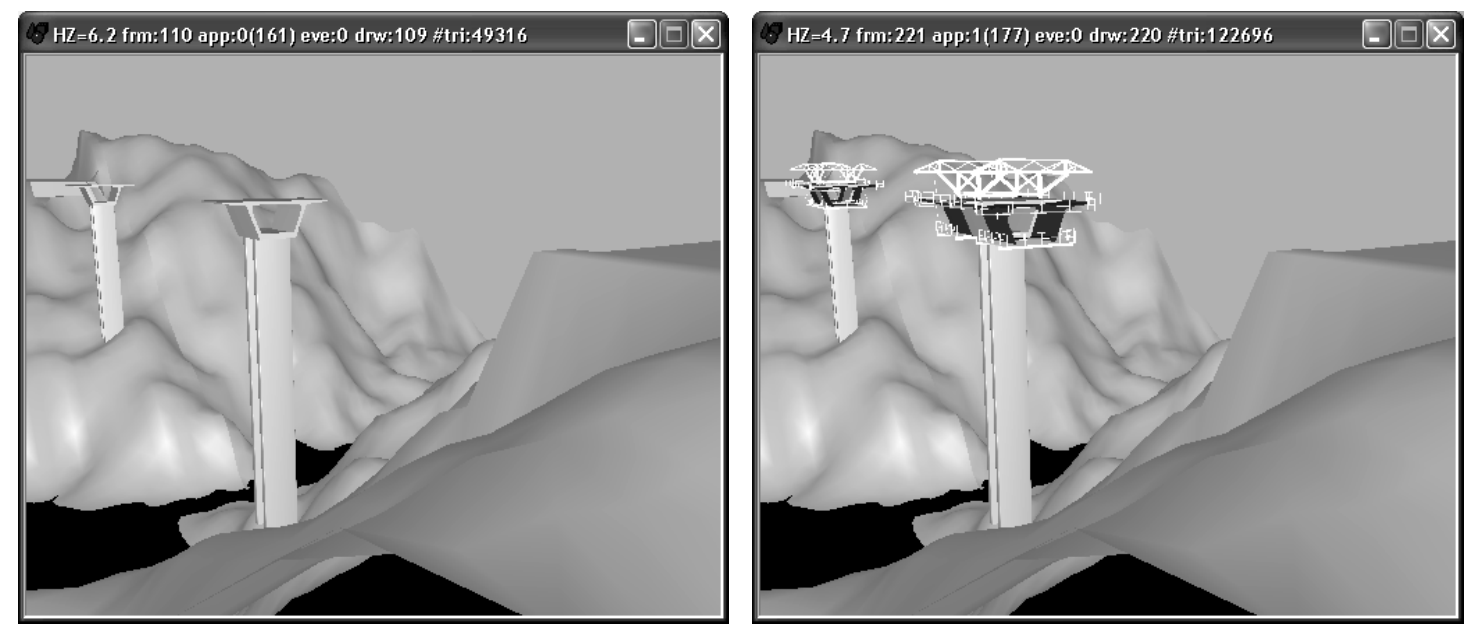

Figure 10: Placing the initial pillars and segments and the advanced equipment.

After this, a form traveller is placed on each segment. The construction of the deck is defined symmetrically in relation to each pillar and simultaneously. For the simulation of the first cantilever segment (in each span), the four form travellers, the corresponding work platforms and the formwork components are included in the scenario (Fig. 10). When showing the virtual performance the teacher must indicate the technical reasons for this procedure.

Once the first segments have been concreted, the construction of the cantilevered deck takes place. In each phase, two pairs of segments are defined. For each new segment the following steps are established: raising the form traveller; moving the rails in the same direction as the construction (relocating them on the latest segment to have been concreted); moving 
the form traveller on the rails, positioning it in the zone of the next segment to be made; concrete the segment (Fig. 11).
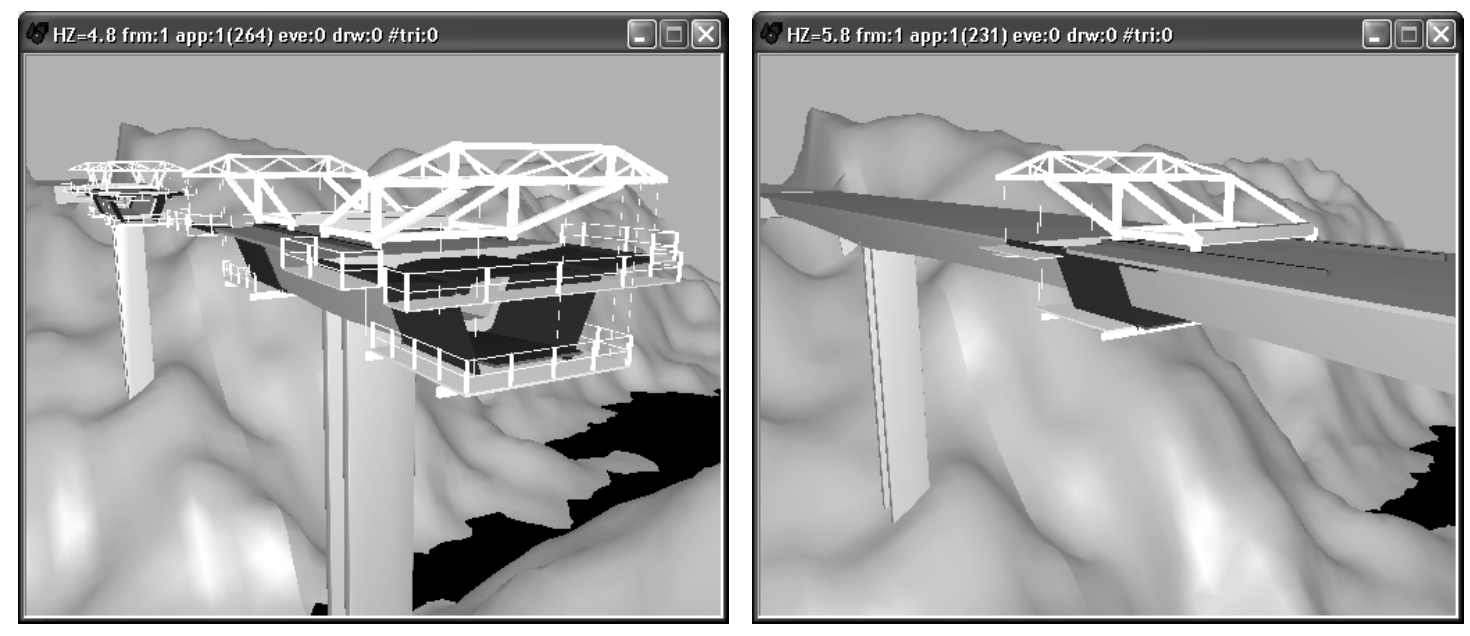

Figure 11: Movement of the advanced equipment and concreting the closing segment.

Using one of the form travellers, the closing segment, in the middle of the central span, is then concreted (Fig. 11). Finally, the zone of the deck near the supports is constructed, the false work resting on the ground (Fig. 12). After this, the bridge is complete.
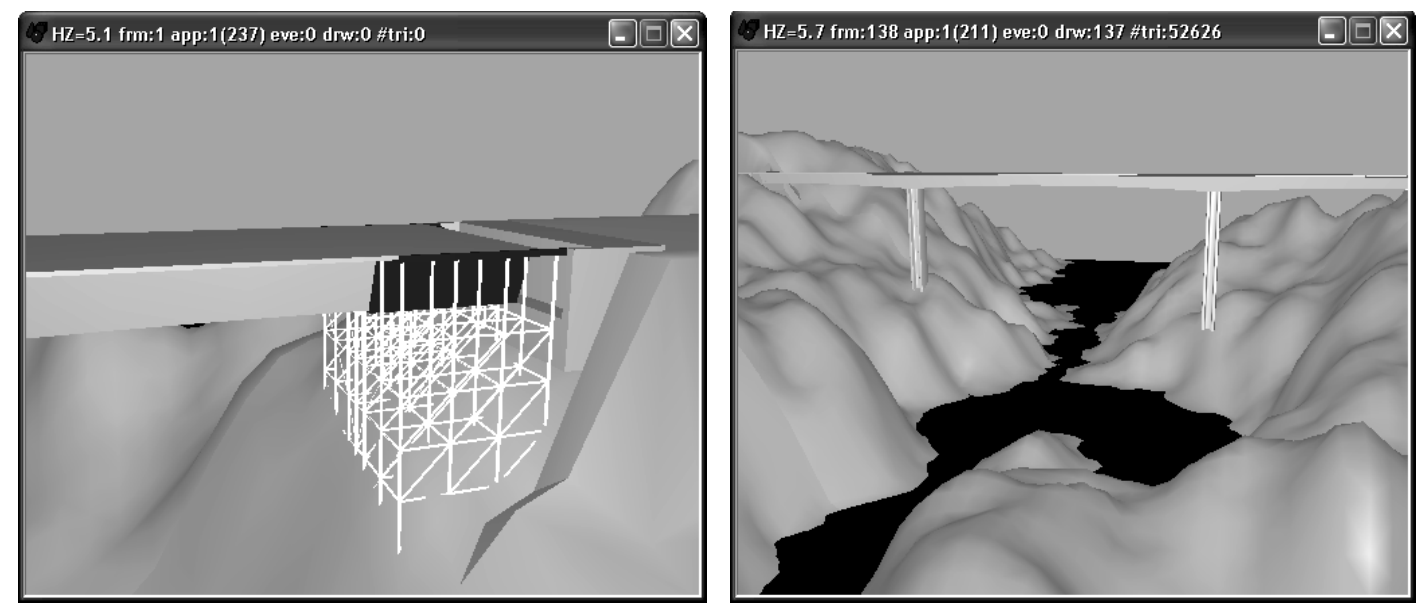

Figure 12: Concreting above the false work near the abutment and the complete bridge.

Moving the camera closer to the model of the bridge and applying to it routes around the zone of interest, it is possible to visualize the details of the form of the components involved in the construction process. In this way, the student can interact with the virtual model, following the sequence specifications and observing the details of the configurations of the elements involved. The camera can also be moved to inside the deck, so the students can observe the changes of interior configure of the deck.

\section{LEARNING ASPECTS}

The models are actually used in face-to-face classes of disciplines of Civil Engineering curriculum: Technical Drawing ( $1^{\text {st }}$ year), Construction Process ( $4^{\text {th }}$ year) and Bridges ( $5^{\text {th }}$ year). The traditional way to present the curricular subjects involved in those virtual models are $2 \mathrm{D}$ 
layouts or pictures. Now, the teacher interacts with the 3D models showing the sequence construction and the constitution of the modelled building element. Essentially, the models are used to introduce new issues.

As in Technical Drawing, students have to define and draw structural plants over the architectural layouts, the virtual model of the wall helps to explain the connection between the architectural drawings and the structural solutions needed to support the house configuration. Some indication must be assumed when choosing a structural solution in order to minimize the unpleasant visual appearance in the interior of a house when structural elements (beans, columns, ...) are included in it. The students are $1^{\text {st }}$ year degree, so they have some difficulty to understand the spatial localization of the structural elements and how they must be built and located almost inside the walls. The relations between the architectural configurations and the structural elements in a building are well explained following the virtual exhibition of the wall's construction.

In the discipline of Construction Process, in order to prepare students to visit real work places, the teacher shows the construction animation and explains some aspects of the construction process of the wall. Namely, the way the net of irons is defined inside a bean or a column and specially the complexity of the connexion between the distinct types of irons near the zone where the structural elements connect each other. In order to clearly explain this issue related to the structural elements, the iron nets were created as 3D models with distinct colours, and they appear on the virtual scenario following a specific planned schedule. The type, sequence and thickness of each vertical panel that composes a cavity wall is well presented in the virtual model showing step by step the relative position between each other. The configuration details of each construction element that composes the complete wall can be clearly observed manipulating the virtual scenario of the wall's construction.

The construction model of a bridge particularly shows the complexity associated to the concrete work of the deck bridge that is done in a symmetric way. The model also shows the way of displacement of the advanced equipment. In class, the professor must explain way the process must follow that sequence of steps and the movement of the equipment devices. When the students, of the $5^{\text {th }}$ year, go to the work place they can observe the complexity and the sequence of construction previously explained.

The students can also interact with those models. For that, the models were posted on the Internet pages of undergraduate Civil Engineering. The student will be able to interact with the application EonX, which can be accessed at EONViewer [11]. This type of didactic material can be used also in distance learning based on e-learning technology.

\section{CONCLUSIONS}

It has been demonstrated, through the examples presented here, how the technology of virtual reality can be used in the elaboration of teaching material of educational interest in the area of construction processes.

The models generated represent building in two standard situations. The student can interact with the virtual model in such a way that he can set in motion the construction sequence demanded by actual construction work, observe the methodology applied, analyse in detail every component of the work and the equipment needed to support the construction process and observe how the different pieces of a construction element mesh with each other and become incorporated into the model. These models are used in disciplines involving construction in courses in Civil Engineering and Architecture administered by the Technical University of Lisbon. They can be used in classroom-based education and in distance learning supported by e-learning technology. 


\section{ACKNOWLEDGEMENTS}

The Foundation of Science financially supported the research projects involved in this work and Technology (FCT) through funds attributed by the FEDER program.

\section{REFERENCES}

[1] Retik, A. (1997). Planning and monitoring of construction projects using Virtual Reality projects, Project Management Journal, No. 3, 28-32

[2] 4D CAD Research Group, Centre for Integrated Facility Engineering, Stanford University, from http://www.stanford.edu/group/4D/, accessed on 12-12-2006

[3] Burdea, G.; Coiffet, P. (2003). Virtual Reality technology, 2ed. John Wesley \& Sons

[4] VTT, Helsinki, Finland, Building, built environment, http://www.vtt.fi/palvelut/cluster6/?lang=en, accessed on 12-12-2006

[5] Leinonen, J.; Kähkönen, K.; Retik, A. (2003). New construction management practice based on the virtual reality technology, Raja, R.A.; Flood, I.; William, J.; O’Brien (Editors), 4D CAD and Visualization in Construction: Developments and Applications, A.A. Balkema Publishers, 75-100

[6] Sampaio, A.; Henriques, P.; Studer, P. (2004). A virtual environment tool applied to visualize construction processes, Proceedings of TP.CG.04: Theory and Practice of Computer Graphics Conference, Bournemouth (U.K.), 78-85

[7] Introduction to working in EON Studio, EON Reality, Inc. (2003)

[8] Sampaio, A. (2003), Geometric modelling of box girder deck for integrated bridge graphical system, International Journal of Automation in Construction, No. 12, Issue 1, 55-66

[9] Sampaio, A.; Braz, H.; Silva, L.; Lopes, B.; Gouveia, R. (2002). Graphic representation of bridges system: right bridges (in portuguese), report DTC/ ICIST $n^{\circ}$ 06/02, Lisbon, 2002

[10] The Bridgebuilder formtraveller, Norwegian bridge building expertise, http://www.nrsas.com/ accessed on 2004

[11] EON Viewer, http://www.eonreality.com/, accessed on 12-12-2006 